\title{
SURVEY ON EFFICIENT PLUG-IN HYBRID VEHICLE CHARGING
}

\author{
Pooja S. Pawar ${ }^{1}$, D. M. Chandwadkar ${ }^{2}$ \\ ${ }^{I}$ Electronics and Telecommunication Department, K.K.Wagh College of Engineering, Nashik, India \\ ${ }^{2}$ Electronics and Telecommunication Department, K.K.Wagh College of Engineering, Nashik, India \\ pujapawar198847@gmail.com,dmchandwadkar@kkwagh.edu.in
}

\begin{abstract}
Our future depends upon the renewable energy sources. Since many years vehicles have relied on combustion fuel like oil and diesel, which will create problem in near future as there are limited reserves of fossil fuels. Hence the most important fact is to preserve energy. So, plug-in hybrid vehicle (PHEV) is good and effective solution for eco-friendly transportation system. Therefore, in this paper a plug-in hybrid vehicle approach is presented along with portable solar panel mounted on it to charge battery. As solar panel is less efficient, a new technique called external light trapping is presented. A 3D printed parabolic concentrator is used for this purpose. It redirects reflected photons back to solar cells and hence due to multiple reflections its power conversion efficiency increases. If in any case, battery run out of charge then to charge it mobile chargers (MC) are used. An android application is developed to support PHEV mobility. It provides full support to driver through its various functions like monitoring of battery, prediction of range it can travel with current battery state and its location. The mobile server based on queuing approach determines design parameter for such mobile charging system. An NJN (nearest-job-next) strategy is used to serve this purpose. In NJN, MC serves next closest PHEV when its current job is done. Moreover, driver can reserve charging slot based on their availability. So, in short our main purpose is to reduce carbon dioxide emission and mitigate PHEV driver range anxiety problem.
\end{abstract}

Keywords: Battery charging, 3D printed parabolic concentrator, Queuing theory, slot booking, Plug-in Hybrid Vehicle.

\section{INTRODUCTION}

In recent decades, the oil consumption has grown at a higher rate in the transportation sector. Statistical analysis has shown that, with the current rate of discovery of new oil reserves and the current consumption rate, the world oil reserve will be depleted by 2049 [1]. The increase in oil consumption is due to demands of vehicles powered by conventional internal combustion engines. The heavy use of gasoline vehicles has rattling contribution towards increasing pollution in developed and developing countries [2]. Since these leads to increase issues related to environment so, stringent standards have been developed by government agencies for fuel intake and release [3]. Hence a postulated sequence of possible events shows that Electric Vehicles (EVs) is a perfect root to handle this problem of environment related issue as they don't consume fuel therefore don't emit harmful gases. This property of electric vehicles will help to lesson the strain on city life as they produce zero local emissions and provide the silent driving [2]. When the condition comes like there is regular start and stop and the trip to be encountered is small then electric vehicles would have the same characteristics as normal engine at reduced price when we compare to regular oil and diesel based vehicles on road driving [2,4].

According to the estimation available in [3], seventy percent of population in city travel day-to-day and cover almost $100 \mathrm{~km}$. This causes an environmental pollution problem. The short range of electric vehicles would be feasible for daily trip. The frequent start and stop driving characteristics helps in increasing the range of electric vehicles. Thus, electric vehicles provide a clean transportation without any emission.

Figure 1. shows a comparison of annual operational costs among different vehicle architectures [4].

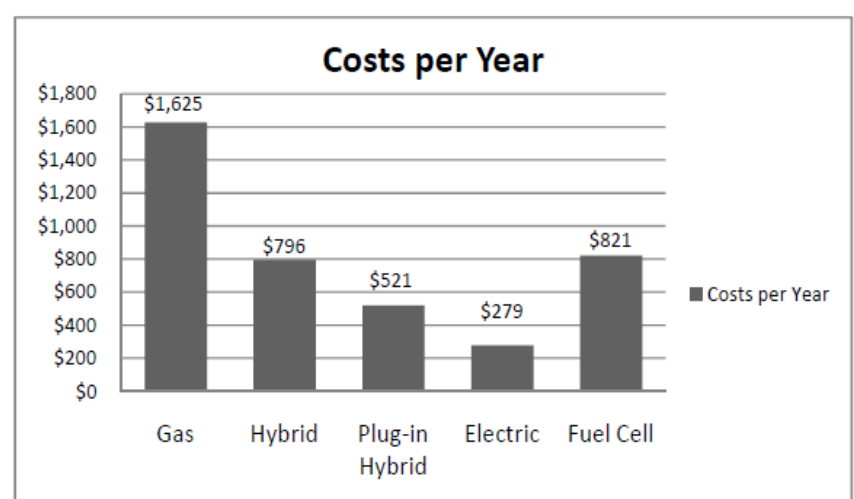

Fig.1. Annual operational cost comparison for different vehicle architectures.

Due to tremendous evolvement in vehicle design, as Fig. 2 reflects that the design becomes more complicated in order to have the required improvement in its functions [5]. 


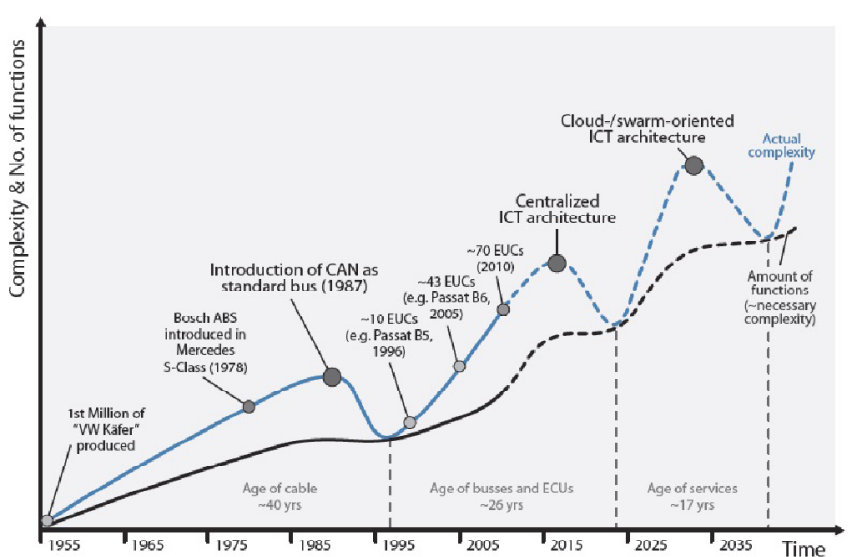

Fig. 2. Evolution of complexity in the automotive domain

Since we want to overcome the limited range trouble of the electric vehicles, plug-in hybrid electric vehicle is proposed. PHEV is similar to a hybrid electric vehicle except that the on board energy storage unit can be recharged from the electricity available from the grid similar to that of electric vehicles [6]. Though PHEV reduce emission and range anxiety problem, it will increase the electricity demand from grid. So, naturally load demand will increase on grid. Hence, to alleviate this problem a portable solar permanently mounted on vehicle will be a good solution. But then also the problem comes with the solar panel efficiency, so to increase its efficiency an external light trap is made so that it can concentrate most of the sun energy towards the solar cell. This system improves the solar efficiency without changing the internal structure of solar cell. The external light trap is nothing but a 3D printed parabolic concentrator to externally trap most of the light towards solar cell.

Another problem is that PHEV cannot depend solely on renewable energy sources. That's why in any case if battery runs out of charge then complementary technique to charge the battery is through plug-in i.e. external charging. There are several options to charge the battery. We can classify plug-in charging into three categories: level 1, 2 and 3. A level-1 charger is installed into a household plug and can deliver very less power. Moreover, charging time is up to 10-12 hours. A level-2 charger can deliver more power than level-1 but it also requires 8-10 hours of charging. A level-3 is a fast charging system which can deliver high power and trim charging time to less than an hour. So, most of vehicle owner prefer level-3 charger due to reduced time.

Henceforth, we propose a mobile serving system as an substitute to recharge the battery. We propose queuing based model to perform mobile charging process. An NJN service strategy is used by the mobile server to serve the charging request of mobile client. This is a most efficient technique rather than first-come-first-serve (FCFS) one.

\section{LITERATURE REVIEW}

Vehicles are of most important to cope up with fast world. Researches are going on how to reduce the emission along with reduced cost of car so that it can be affordable to the consumer to buy it. Even though traditional vehicle price is less than hybrid vehicle it contributes to environmental pollution. One thing that restricts the consumer to buy electric car is range anxiety problem i.e. what will happen if battery becomes low in mid way, a person will be unable to cover large distance like for a long journey. Let's have a look on different strategy used to charge the battery.

The author considered an agent-based model that deals with the demographic and spatial considerations to dig out the effect of PHEV charging [7]. PHEVs are modelled as agents, which can decide mode of charging and travel plan. The PHEV are charged more during office hours and they are charged less during off time. Its benefit is fast charging can be done but load on grid increases.

The author in [8] studied the result of charging a plug-in hybrid vehicle through public utility and grids. This paper presents the scenario of conversion of LDV to PHEV implications to overall emissions as electricity replaces gasoline. It concludes with a discussion about grid impacts due to PHEV load.

S. Huang et al. [9] presents the outcome of grid rates on PHEV users. It suggests that PHEV will have more weightage in areas where grid prices are less. Moreover, time of day will affect the pricing rate.

M. Nilsson,[10] presents the phenomenon of range anxiety of electric vehicles. S.A. Cutler, B, Schmalberger, and Cecil Rivers [11] develop an solar ecosystem which work intelligently with electric vehicles. The solar stations will require a master that will control the electricity supply and communicate with the grid and also with the solar station. It reduces the load on grid but increases the communication overhead.

T. E. Stamati, P. Bauer [12] presents dynamic on road charging concept. Contactless Power Transfer (CPT) are used to wirelessly charge electric vehicles. It can be put beneath the road so that it can charge vehicles while running on it. But the drawback is that an inverter is required for each primary winding to produce the current supply which contains frequency of higher value and practical implementation cannot be possible.

All above technique either consider charging at home or from grid. There is another approach to charge the battery called mobile charger (MC). It undertakes the concept of queuing theory to serve the charge request. Now take a look on various techniques to increase solar cell efficiency.

We can improve the performance of thick solar cells by reducing its thickness given that absorptance remains constant. So, large efforts have been made to obtain high absorptance in thin solar cells by modifications of the solar cell surface to obtain internal light trapping [13, 14]. However, these internal cell modifications don't have a positive impact on the solar cells material quality and its characteristics. 
In case of nano-crystalline silicon the growth of a solar cell on top of a textured scattering surface is challenging [15-17] while for organic solar cells effectiveness of texturing is less[18]. It is therefore breakthrough task to obtain the full theoretical capability of internal light trapping for solar cells methods [19] and hence there is a need for more efficient light trapping.

Hence we demonstrate an external light trapping method that will replace existing internal trapping methods more efficiently without affecting any textured quality of solar cells [20]. Therefore, 3D printed large concentrator arrays will alleviate the need of internal trapping providing more efficiency than previous work and even cost effective.

\section{PROPOSED SYSTEM}

The proposed system is develop to overcome fuel dependency problem with an efficient approach of charging vehicle with renewable energy sources and provide mobile charging to the vehicle. The proposed system is divided into following parts:

a) Sun energy capturing module

b) Mobile charging

c) Slot booking

d) Security

\section{A) SUN ENERGY CAPTURING MODULE}

In our research work we are going to use $3 \mathrm{D}$ printed parabolic concentrator as external light trapping agent. This 3D printed parabolic concentrator is mounted on solar cell. An array of this concentrator is placed on solar cell rather than placing a single concentrator on whole panel. This approach reduces the implementation cost and complexity. This is cost effective way to improve solar efficiency. Hence, we can get more power conversion from it. We proposed several possible designs for an array of concentrators like a square, hexagonal and circular parabolic concentrators to improve EQE of an organic solar cell. Moreover, the sun tracking system is implemented to track the sun to improve the efficiency.

\section{B) MOBILE CHARGING}

We know that sun energy varies due to weather condition. In any case if there is not sufficient amount of sun energy to charge the battery in order to complete the whole trip there should be an alternative to charge it. A mobile charging technique is suggested to perform such work. This strategy is developed based on queuing model and uses NJN (nearest-job-next) based service to serve different owners. The mobile server will precede the request according to NJN strategy. It means the mobile server will locate nearby mobile charger and schedule charging of owners accordingly.

\section{C) SLOT BOOKING}

The module is developed to book the charging station slot if required. It searches for nearby charging station and book slot accordingly.

\section{D) SECURITY}

The security of vehicle is one of the key issues. Hence, we propose an ignition system approach using mobile phone to make access of vehicles.

\section{E) PROPOSED SYSTEM OVERVIEW}

The proposed system based on concept of external charging through renewable energy sources i.e. solar energy is shown Figure 3. The sun energy capturing module is attached to solar cell. In our circuit, there will be ARM7 controller which operates the battery and display the respective result on LCD. An android application is developed to monitor battery status and predict the range it can travel with current battery status and its own location. So, if state of battery fall below threshold level it will send the message to the server which will contain all vehicle information and its location. The mobile server accepts the entire request from different vehicle owners and develops a strategy to serve them. This is what we call mobile charging system. Moreover, if charging station is nearby and vehicle can travel up to that location, we can book the charging slot with the help of android application. Even though battery is full the vehicle will not start until relay is operated. This relay is operated with the help of mobile phone. GSM technology is used to operate it not Bluetooth as there are chances of security key theft due to hacking concept which is more in wireless network.

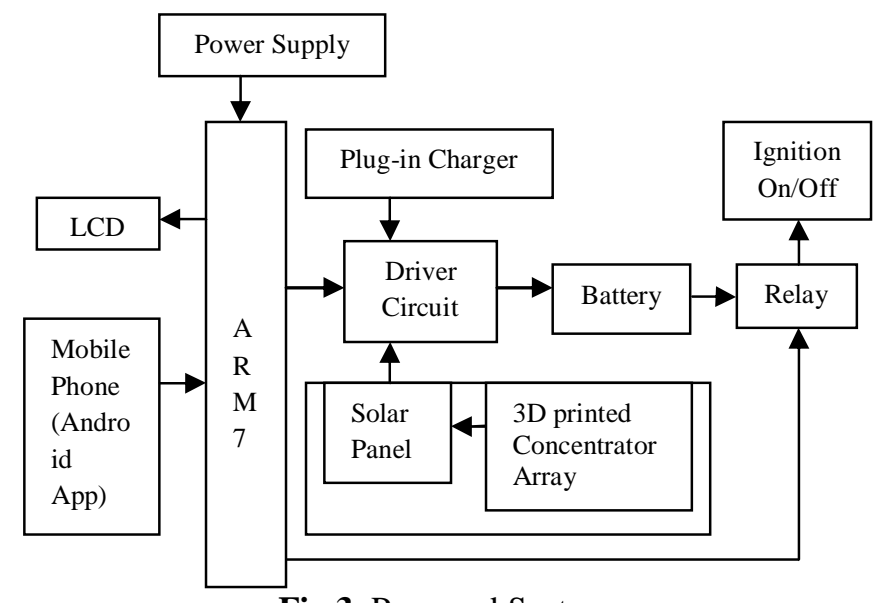

Fig.3. Proposed System

\section{CONCLUSION}

In this paper, we have gone through various charging technologies and schemes for plug-in hybrid vehicle charging. Moreover, we have studied technique of improving solar efficiency through external trapping. Ours charging system provides novel technique to serve battery replenishment. An NJN strategy is discovered for a movable serving system. In this, the request related to charging from PHEVs is demonstrated by the distribution named Poisson. Hence, the movable device serves the next adjacent PHEV when the on going request is completed. We proposed several possible designs for an array of concentrators that can be used along with solar cell. Thus, square, hexagonal and circular parabolic concentrators considered to improve $\mathrm{EQE}$ of solar cell. In order to realize a high transmittance 
fabrication accuracy should be high. Also we can book charging slot hence providing an efficient way to get rid of range anxiety problem and reduce harmful emissions of gases that often occur in ICE vehicles.

\section{ACKNOWLEDGMENT}

The authors acknowledge the breakthrough discussions with the help of K. K. Wagh Institute of Engineering Education and Research, Nasik, India for providing research facilities.

\section{REFERENCES}

[1] BP Statistical Review of World Energy, June 2007, www.bp.com/statisticalreview.

[2] J. Terras, A. Neves, D. Sousa and A. Roque, "Modeling and Simulation of a Commercial Electric Vehicle," 13th International IEEE Annual Conference on Intelligent Transportation Systems, September 2010.

[3] C.C. Chan, A. Bouscayrol, and K. Chen. "Electric, Hybrid, and Fuel-Cell Vehicles: Architectures and Modeling," IEEE Transactions on Vehicular Technology, February 2010.

[4] J. Randolph and G. Masters, Energy for Sustainability: Technology, Planning, Policy. Island Press, 2008.

[5] S. Chakraborty, M. Lukasiewycz, C. Buckl, S. Fahmy, N. Chang, S. Park, Y. Kim, P. Leteinturier, H. Adlkofer, "Embedded Systems and Software Challenges in Electric Vehicles", Design, Automation and Test in Europe Conference and Exhibition(DATE), 2012.

[6] P. Fajiri and B. Asaei, "Plug-in Hybrid Conversion of a Series Hybrid Electric Vehicle and Simulation Comparison," 11th International Conference on Optimization of Electrical and Electronic Equipment, May 2008.

[7] M. Eppstein, D. Grover, J. Marshall, and D. Rizzo, “An agent-based model to study market penetration of plugin hybrid electric vehicles," Energy Policy, vol. 39, no. 6, pp. 3789-3802, Jun. 2011

[8] M. K. Meyer, K. Schneider, and R. Pratt, Impacts Assessment of Plug- In Hybrid Vehicles on Electric Utilities and Regional U.S. Power Grids Part 1: Technical Analysis. Richland, WA, USA: Pacific Northwest National Laboratory, 2007.

[9] S. Huang et al. (2011, Mar.). The effects of electricity pricing on PHEV competitiveness. Energy Policy[Online].39(3),pp.1552-1561.Available: http://www.sciencedirect.com/science/article/pii/ S0301421510009298.

[10]M. Nilsson, "Electric vehicles: The phenomenon of range anxiety," ELVIRE, Gif-sur-Yvette Cedex, France, ELVIRE Consortium FP7CICT- 2009C4-249105, 2011.

[11]S.A. Cutler, B, Schmalberger, and Cecil Rivers, "An Intelligent Solar Ecosystem with Electric Vehicles", Electric Vehicle Conference(IEVC), 2012.

[12]T. E. Stamati, P. Bauer, "On-road charging of Electric Vehicles", ITEC, 2013.

[13] J. Zhao, A. Wang, M. A. Green, F. Ferrazza, "19.8\% efficient "honeycomb" textured multi crystalline and
24.4\% monocrystalline silicon solar cells," Appl. Phys. Lett. 73 (14) (1998) 1991-1993.

[14] K.Masuko, M.Shigematsu, T.Hashiguchi, D.Fujishima, M.Kai, N.Yoshimura, T.Yamaguchi, Y.Ichihashi, T.Mishima, N.Matsubara, T.Yamanishi, T.Takahama ,M.Taguchi, E.Maruyama, S.Okamoto, Achievement of more than $25 \%$ conversion efficiency with crystalline silicon heterojunction solar cell, IEEE J.Photovolta. 4(6) (2014) 1433-1435.

[15] T.Matsui, M.Tsukiji, H.Saika, T.Toyama, H.Okamoto, Influence of substrate texture on microstructure and photovoltaic performances of thin film polycrystalline silicon solar cells, J. Cryst. Growth 299 (2002) 11521156.

[16]R. Schropp, J.Rath, H.Li, Growth mechanism of nanocrystalline silicon at the phase transition and its application in thin film solarcells, J.Cryst. Growth 311 (2009) 760-764.

[17] Y. Kuang, M. DiVece, J. K. Rath, L. vanDijk, R. E. I. Schropp, Elongated nanos- tructures for radial junction solar cells, Rep. Prog. Phys. 76 (10) (2013) 106502.

[18]Z. Tang, W.Tress, O.Inganas, Light trapping in thin film organic solar cells, Mater.Today17 (8) (2014) 389396.

[19] A.Polman, H.A.Atwater, Photonic design principles for ultra high-efficiency photovoltaics, Nat.Mater.11 (2012) 174-177.

[20]3D printed light trap arrays enhance solar cell performance, April 2015, www.3dprint.com/58515/solar-cell-light-trap-array 